\title{
Organization of planning in transport construction
}

\author{
Ruben Kazaryan $^{1 *}$, Peraskovya Andreeva ${ }^{1}$, and Natalya Galaeva ${ }^{1}$ \\ ${ }^{1}$ Moscow State University of Civil Engineering, 26 Yaroslavskoe shosse, Moscow, 129337, Russia
}

\begin{abstract}
Purpose. Development of methods and models of economic efficiency of the integrated use of various modes of transport in the interests of ensuring national security of the state. Methods. System analysis, logical-mathematical modeling, systems theory, economic-visual modeling, research methods of operations, economic and mathematical methods. Results. The paper discusses the need for the application of economic and mathematical models in the design of transport construction (model of "moving the earth masses", linear programming model, design of the "red line" on the longitudinal profile, dynamic programming model). Conclusion. The difficult stage of the transition of economic and mathematical analysis from the verbal description of the system process to the elemental base of the mathematical apparatus. Most research models of operations are designed for single criteria. Economic and mathematical modeling allows the effect of "private optimization".
\end{abstract}

\section{Introduction}

Nearly all of the originally developed models were autonomous - monadic, i.e. models oriented to the solution of any particular problem. To build an integrated model, these particular models need to be aggregated, but there is a risk of losing some of the links between private models, their mutual influence. On the other hand, the experience of using economic and mathematical models has shown that the tendency to complicate models or their aggregation is not always justified. In a market economy, profit is of particular importance. It is a source of self-financing of the economic and social development of an enterprise. Profit is one of the summary indicators characterizing production efficiency. It represents the final financial result of production and economic activity of an enterprise. Profitability characterizes the final financial result and the efficiency of production and economic activity. These basic economic indicators largely depend on the organization of transport construction work (proper placement of equipment and labor resources, the degree of use of fixed production assets, and the coordinated activities of production units in the production process). Assessment of the efficiency of the method of organizing and the way of progressing the work should be carried out taking into account a system of criteria (economic and production). These issues are resolved in the process of production planning

\footnotetext{
* Corresponding author: r.kazarian@mail.ru
} 
and management. In this case, an important role is played by the choice of the method of organizing and the way of progressing the work. [1-3, 4-7].

\section{Materials and Methods}

General scientific methods were used - systems analysis, logical and mathematical modeling, systems theory and others, as well as methods of operation study and economic and mathematical methods. To solve some elements of the task of developing methods and models of economic efficiency of the integrated use of various modes of transport in the interests of ensuring the national security of the country, it is necessary to consider the most essential aspects of the task: to analyze the state of science and practice in the field of transportation for ensuring the national security of the country; to develop criteria for the assessment of efficiency of transportation for ensuring the national security of the country; to develop economic and mathematical models of the integrated use of various types of transport in the interests of ensuring the national security of the country; to develop methods of economic integrated use of transport in the interests of ensuring the national security of the country; to ensure the development of scientific and methodological recommendations for improving the economic efficiency of transportation for ensuring the national security of the country.

\section{Results}

The use of economic and mathematical models in transport construction allows drawing the following conclusions [1-8].

First, the most difficult stage of economic and mathematical analysis is the transition from a verbal description of a system, a process to a mathematical one. Ignoring this provision led to the description of complex processes by simplified mathematical models.

Secondly, even a mathematically correctly built model may not always be a good economic and mathematical model. It is necessary to study the issue of the conformity of the model with the studied economic phenomenon. There is still an opinion that the main goal of economic and mathematical modeling is to obtain an optimal solution, although the main question is whether this mathematical model can be used to analyze the studied economic situation. However, this task refers to the problems of not mathematical, but economic science, which should be regarded as primary. This statement is easily proved by the experience of mathematical modeling of technical systems. Usually, mathematicians are involved in building mathematical models of technical systems, and problem statement is a matter of engineers. Different levels of mathematical training of engineers and engineering training of mathematicians do not always allow creating equally high-quality models from the perspective of the requirements of one and the other. Hence the problem of the adequacy of economic and mathematical models, which remains very relevant today. Adequacy (conformity) of the model can be considered as a conditional concept. There can be no absolute correspondence between the model and the object of modeling, otherwise it would not be the model, but the object itself. For example, a car may have several models depending on the goals: a model-simulator for learning to drive a car does not match its shape and size (i.e. in this sense, it is not adequate to a car), but it is quite adequate to it in terms of control processes (steering wheel, pedals, cab fully comply with the conditions of the driver when driving a car);

- model of a car, built for the mock-up design of a garage, is only externally adequate to the original, but has nothing to do with it in terms of control systems, power supply, 
electrical equipment, etc. Both models can be considered adequate to the car, but each is adequate only from the position of task set before the modeling. This example shows that by mathematical abstraction, we often separate the form of the problem being solved from its content.

Thirdly, the problem of the criterion used in the model arises. In general, in modeling, the criterion problem is considered the most important component in the construction of a model. Most of the operation research models were originally designed for single criterion. The same can be said about the models used in transport construction in the seventies and eighties. As a rule, these were cost (economic) criteria: the cost of construction, transportation of materials, equipment downtime, losses from road accidents, etc. At the same time, organizational, socio-economic, environmental, technological, anthropotechnical and other factors (criteria) that could significantly change the model itself, as well as the efficiency of its use, were ignored.

Fourthly, distrust of economic and mathematical models in the seventies and eighties was associated with the extreme nature of the models, which led to the "squeezing of reserves". The linear programming, queuing, inventory management, and some other models have the following target function model:

$$
C_{\sum}=\sum_{i=1}^{n} \sum_{j=1}^{m} x_{i j} c_{i j} \rightarrow \min (\max ),
$$

where $C_{\Sigma}$ - total losses on transportation of construction materials from $n$ construction industry enterprises to $m$ work sites; $x_{i j}$ - the volume of supplies of materials from the $i$-th enterprise to the $j$-th object; $c_{i j}$ - the unit cost.

Extremality of the model (tending to a minimum or maximum) leads to the cheapest transportation option (the cheapest storage of materials, etc.), but during the construction process, there are constantly unforeseen situations when you have to pay for a simple downtime of rail cars on the tracks due to bad weather conditions (downtime due to low temperature or rain). This requires a reserve of forces and means, which is excluded in the process of economic and mathematical modeling.

Fifthly, with the economic and mathematical modeling, the effect of "private optimization" is allowed. Its essence can be explained by the example of queuing models. When calculating the number of dump trucks working together with one excavator, an extreme model of the following type is used:

$$
C_{\Sigma}^{\text {downtime }}=P_{\mathrm{e}} C_{\mathrm{e}}+v C_{\mathrm{dump}} \rightarrow \min ,
$$

where $C_{\Sigma}^{\text {downtime }}$ - the total loss from downtime of the transport unit, rub.; $P_{e}$ - the probability of excavator's downtime; $C_{e}-$ the cost of machine-shift of an excavator, rub.; $v$ - the average number of dump trucks for loading, units/shift; $C_{\text {dump }}$ - the cost of machine-shift of a dump truck, rub.

\section{Discussion}

Managers and users of economic systems know much better the content of mathematical abstraction systems with frequently separated elements of the form of the problem being solved from its content than mathematics. The latter cannot spend so much time and effort to learn the content of each specific problem with such depth that those who will directly solve the problem have, taking into account the results of modeling. For example, using only an economic criterion, the maximum allowable range of supply of asphalt concrete 
mixture to the line from the asphalt concrete mixing plant may be $70 \mathrm{~km}$. However, if we take into account the technological criterion (cooling temperature of the mixture during transportation), this distance may be unacceptable, since the required temperature of the mixture delivery to the paver at such a distance will be lower than the required one. For example, if the maximum distance of transportation according to temperature conditions turned out to be $50 \mathrm{~km}$, then $50 \mathrm{~km}$ should be taken into account.

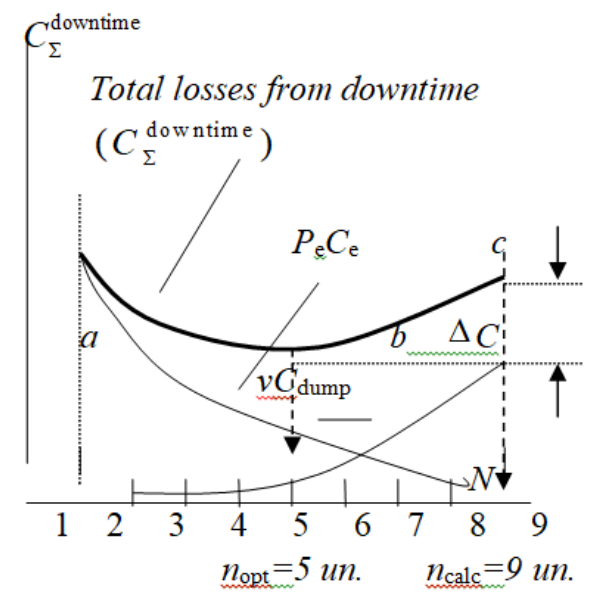

Fig. 1. Illustration of the effect of "private optimization". First stage.

The meaning of the "private optimization" effect is illustrated in Figure 1 as the dependence of losses on the excavator's downtime on the number of dump trucks in the subdivision (curve $a$ ), losses on the dump trucks' downtime (curve $b$ ), and total losses (curve $c$ ). Solving the problem of minimizing the cost of subdivision's downtime using a queuing model will result in an optimal number of dump trucks equal to 5 units. Using traditional calculation, this number is equal to 9 units. With $n_{\text {calc }}=9$ units, it is possible to lose $\sqcup C$ rubles from the dump trucks' downtime. But with 9 dump trucks, the sand removal rate will be higher, and the work can be completed ahead of schedule (Fig. 2).

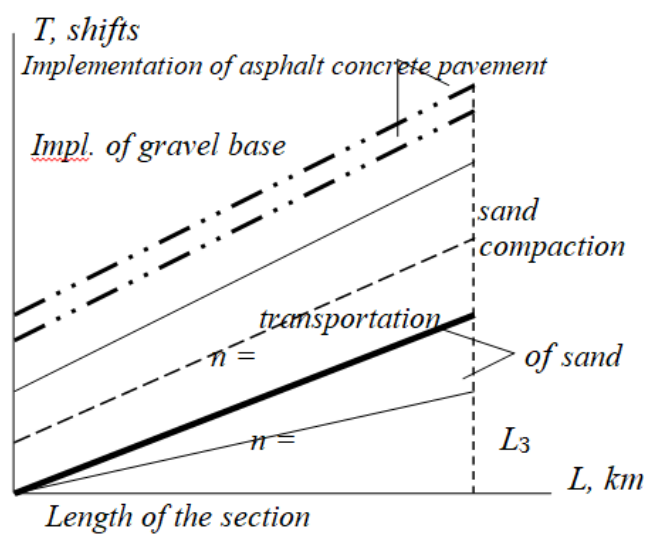

Fig. 2. Illustration of the effect of "private optimization". Second stage.

Capacities of industrial enterprises are calculated using various methods depending on the type of enterprise. At the same time, two main schemes are viewed: 
1) the company's products must be sold immediately (concrete, mortar, hot and warm asphalt concrete mixtures);

2) products can be stored (crushed stone, sand, reinforced concrete structures).

In the first case, the capacity must be consistent with the rate of consumption of the mixtures (flow rate).

The hourly productivity of an enterprise immediately selling its products is calculated by the formula:

$$
\mathrm{P}_{\mathrm{H}}=\frac{v Q_{1}\left(1+K_{\mathrm{L}}\right)}{\mathrm{K}_{\mathrm{N}} \cdot t},
$$

where $\sqcup$ - flow rate, $\mathrm{km} / \mathrm{h} ; Q_{1}$ - product demand per $1 \mathrm{~km}$ of road $\left(\mathrm{m}^{3} / \mathrm{km} ; \mathrm{t} / \mathrm{km}\right) ; K_{\mathrm{L}}$ - loss factor of products during transportation and paving $(0.01-0.05) ; K_{\mathrm{N}}-$ coefficient of non-uniformity of production and paving of products (for asphalt concrete mixing plant and cement concrete mixing plant $=0.9-0.05$, for dump trucks $=0.9$, for asphalt pavers $=0.85-$ $0.95) ; t$ - number of hours per shift.

The productivity of enterprises, part of the products of which can be stored, is calculated according to the following dependency:

$$
\mathrm{P}=\frac{Q_{1} \cdot L\left(1+K_{\mathrm{L}}\right)}{T K_{\mathrm{N}} \cdot t},
$$

where $Q_{1}$ - product demand per $1 \mathrm{~km}$ of $\operatorname{road}\left(\mathrm{m}^{3} / \mathrm{km} ; \mathrm{t} / \mathrm{km}\right) ; L$ - the section of the road for which products may be supplied to the warehouse; $T$ - the number of working days for the period of operation of an enterprise.

If a part of the product $\left(Q_{1}\right)$ is stockpiled and stored, and the other $\left(Q_{2}\right)$ is issued immediately to the construction site, then the volumes of both types of products are calculated using the formulas:

$$
Q_{1}=\frac{\mathrm{P} T_{1} t_{1}+2 K_{\mathrm{N} 1}}{1+K_{\mathrm{L} 1}}
$$

where $\mathrm{P}$ - hourly productivity of the enterprise's leading machine (concrete mixer, stone crusher) in normal (summer) working conditions; $T_{1}$ - the period of time during which the stock is created in the warehouse (work shifts); $t_{1}$ - the number of hours per shift; $K_{\mathrm{N} 1}-$ coefficient of non-uniformity of output $(\varphi-$ coefficient of equipment performance reduction in winter conditions is used); $K_{\mathrm{L} 1}$ - loss rate of products in winter conditions.

$$
Q_{2}=\frac{\mathrm{P} T_{2} t_{2}+2 K_{\mathrm{N} 2}}{1+K_{\mathrm{L} 2}}
$$

The parameters are the same, but for summer conditions.

The total capacity of an enterprise, sufficient to provide construction with volumes of $Q_{1}+Q_{2}$ will be:

$$
\mathrm{P}_{\Sigma}=\frac{Q}{Q_{1}+Q_{2}}=\frac{Q\left(1+K_{\mathrm{L}}\right)}{T_{1} t_{1} \varphi K_{\mathrm{N} 1}+T_{2} t_{2} K_{\mathrm{N} 2}} .
$$


For the most part, the above disadvantages manifested in the seventies and eighties are now easy to overcome, since they affect not the essence of the economic and mathematical methods themselves, but the problems of their construction and use.

\section{Conclusions}

A new impetus to the development of economic and mathematical modeling in our country was received after the nineties with the transition to a market economy. The desire for profit inevitably led to the optimization of solutions for both private and complex problems of economic activity. Special programs for processing information using modern digital technologies, adapting models to the working conditions of specific firms, organizations and enterprises have started to be developed. At the same time, there was a problem of training personnel at various levels of management on the issues of economic and mathematical modeling. The experience of past years has shown that the greatest effect of economic and mathematical modeling can be obtained in the planning and management of production, including in the design of transport facilities. To limit the scope of use of economic and mathematical models only to the design of facilities would be not right and even wrong. The cost of complicating the model should be commensurate with the resulting profits. The greatest flourishing of the use of autonomous economic and mathematical models occurred in the seventies and eighties of the last century, when they were widely used in the design of transport construction (models of "moving earth masses", linear programming models, designing the "red line" on the longitudinal profile, dynamic programming models, and others). It is necessary to focus on the study of issues of multicriteria assessment of alternatives and the integrated use of economic and mathematical models in the interests of ensuring the national security of the country.

\section{References}

1. S. Sinenko, T. Poznakhirko, V. Obodnikov. MATEC Web of Conferences 270, 05008 (2019) https://doi.org/10.1051/matecconf/201927005008

2. S.A. Sinenko, A.O. Feldman IOP Conf. Series: Materials Science and Engineering 463 (2018) 042010. IOP Publishing doi:10.1088/1757-899X/463/4/042010.

3. K. Yu. Losev, V. O. Chulkov, R.R. Kazaryan IOP Conf. Series: Materials Science and Engineering 463 (2018) 032085

4. R.R. Kazaryan MATEC Web of Conferences, 239, (2018)

5. A.A.Volkov, V.O.Chulkov, R.R.Kazaryan, S.A.Sinenko Applied Mechanics and Materials 584-586 (2014) 2681-2684 doi: 16028/www.scientific.net/AMM.584586.2681 ;

6. R.R. Kazaryan, MATEC Web of Conferences, 193, 01009 (2018)

7. R.R. Kazaryan, MATEC Web of Conferences, 193, 04023 (2018)

8. R.R. Kazaryan, MATEC Web of Conferences, 170, 05001 (2018) 